\title{
Improvisational Attitudes: Reflections from Art and Life on Certainty, Failure, and Doubt
}

\section{Amanda Ravetz, Anne Douglas, and Kathleen Coessens}

Improvisation is a form of encounter, unfolding in spaces of uncertainty. It can be a playful response to unknown situations or a necessary tactic for sheer survival. It creates and recreates dialogues with the self and the other. By momentarily capturing the human condition of unrepeatability, it offers a mirror to experience.

This Special Issue draws together diverse projects that nonetheless share approaches to the improvisational. ${ }^{1}$ The authors are artists and researchers from across the domains of visual art, music, and anthropology. They discuss work situated in Belgium, England, Scotland, USA, Mexico, Germany, and India. Their reflections cut across different sites in which practices of improvisation have traction and therefore meaning. They draw on methodical skill and knowledge, arguably the domain of certainty. At the same time they are open to a state of mind in which the next moment is truly indeterminate.

Three of the papers confront questions of failure in life, experiences in which there is a breakdown in what we assume should happen. This, in turn, catalyses improvisation.

Nayanee Basu, as ethnographer, details the experiences of two individuals, an established classical dancer and a director general of prison services in West Bengal. Basu describes and analyses their introduction of dance and theatre into these prison communities. Improvisation works here at a number of levels. The prison as a site represents social and individual failure. The implementation of the dance dramas generates a reflective encounter for prisoners and staff. It questions experiences of inertia within the system. The civic processes slowly bend in response to this new energy, creating the potential for reform.

Amanda Ravetz, as artist and anthropologist, reports on a drawing experiment undertaken collaboratively with Anne Douglas and Kathleen Coessens. Drawing, performed here for its own sake, creates a different quality of space and time within everyday existence. This is a space of reverie. At the same time the experiment frames perceptions of loss and failure, for example around the (in)ability to draw innovatively and with meaning. Reverie opens up two things: the perception of unrepeatability, i.e. not being able to reclaim what has been lost, and the possibility of beginning again. Reverie as a form of improvisation is a "necessary illusion" interweaving hope and loss. This makes it possible to address moments of rupture in which failure itself can signal new beginnings.

Coessens, musician and philosopher, situates improvisation in everyday life as a response to the contingent. The human imagination constructs a pantheon in relation to the unexpected. The world of the gods is without risk as all choices can be revised. It does not fail. This is a condition to which human beings aspire but, Coessens argues, it is ultimately uninteresting. Improvisation is redundant in the world of the gods. In contrast, the human world is uncertain. Human beings encounter the unknown, sometimes clumsily, through whatever skill or knowledge comes to hand. Between these two worlds is the hero who copes with the unexpected and at the same time aspires to the realm of the gods. Improvisation in the arts is situated within the heroic. Artists aspire to overcome failure through improvisatory acts, addressing the unexpected with intention.

The two following papers, one by Anne Douglas and another by Gaelyn and Gustavo Aguilar, represent a shift in affective tone, from failure to doubt. Both critically examine institutional forms: Douglas, through the work of Allan Kaprow, raises doubt about the institution of art itself; Gaelyn and Gustavo Aguilar question the linear thinking of systems of nation state and corporate capital.

Douglas, a visual artist, works closely with Kaprow's questioning of the certainty of art. For Kaprow, art and life do not collapse into each other. Art imitates life, which imitates art, but the feedback loop is never exact. Moreover, life can consume art in a collision between creativity and competition, money and utility, leading to entropy. In an experimental project, Calendar Variations 2010-11, Douglas and a group of artists and researchers worked closely with Kaprow's intentions, re-enacting one of his experimental scores. Improvisatory responses to the score trigger new beginnings and critical positions. This counters the rhetoric of a tired discourse on social art practice. The experience opens up a process of re-defining and re-connecting with the art-life-art dynamic.

Gaelyn and Gustavo Aguilar, anthropologist and musical improviser respectively, draw an important relationship between improvisation as a practice in music and improvisation as a social, cultural, and political practice. The pivotal concept that unites these domains of activity together is the plurality of identity. Plurality opens up improvisatory dialogues of negotiation. These dialogues work with complexity, countering tendencies in the political to "tidy up" identity. Working through their collaborative organisation "Tug," they seek opportunities to address social and cultural transformation. To this end they develop ethnographies that focus on sound, recording experiences in border areas such as Michoacán, one of Mexico's five feeder states for migration into the US, and Maine, one of the US states that borders with Canada. 
The contributions by Gary Peters, Andrew Sneddon, and Chris Williams and Martin Sonderkamp are contained within the institution of art, a constraint that frees them to focus on particular forms of improvisation. This marks a third transition in this Special Issue: from failure in life, to doubting instituted forms, to the tension between the certainty of skill and the fragility of the moment of artistic creation. Improvisation situates itself at the fulcrum of these tensions.

Peters, an improviser in music and a critical theorist, explores improvisation as an aesthetic model of human action. Human practices contain both the greatest degree of certainty and contingency. Improvisation offers a way to cope with this. However, Peters argues against the usual model of improvisation as unexpected and socially communicative. He proposes that artists deploy rigidity and severity to integrate thought and form. They construct a certitude that can confront possible uncertainty. Improvisation is not the outcome of a work, nor the form of the work, but the mechanisms of actions and choices that precede the performance of an artwork. These acts of preparation embed an improvisatory dimension of "practice and correction," of beginnings and rebeginnings, that lead to the development of aesthetic taste and to the certitude of an artistic outcome. Constructed step by step in a solitary dialogue with the self, individual aesthetic judgment is at the heart of the "severe" improviser's practice.

Sneddon, a visual artist, focuses on the journey that an artist might make from intention to realisation, where the breaks between what is imaginable and what is realisable constitute creative opportunities. However painful it may be not to realise an intention, the improvising artist seizes this breakdown. It then becomes possible to give form to what otherwise could not have been imagined or anticipated. Improvisation in the sense of "make shift" or "making do" is also a "making sense of." Sneddon demonstrates this through Tacita Dean's film projects. For example, Sneddon recounts that in the process of making Banewl (1999) Dean intended to film an eclipse. Due to camera failure, she unexpectedly had to redefine her project, refocusing her filming from the sky to the ground.

Williams and Sonderkamp present an opinion piece in the form of a video recording, programme notes, and an interview. As a double bass improviser (Williams) and a dancer (Sonderkamp) they create a piece of work that establishes a strict time limit of one hour, performed to camera and then edited down to 20 minutes. The space is stark and expansive. It includes a stool for the double bass player, an antique leather armchair, and two microphones. All these props become part of the improvisation. For them, free improvisation is an experience of being at the dynamic centre of an unfolding activity, acting in the moment while sensing the whole, and understanding that the movement of each moment has consequences for the next.

In these papers, improvisation acts as a conceptual lens through which to understand particular qualities of experience. The formal preoccupations of art encounter failure in life as a generative opportunity. Conversely, failure in life challenges fixed ideas within art about what improvisational forms should be. The interval between art and life, within which doubt emerges, prompts new forms of experimentation, risk, and possible failure. All three positions_failure, doubt, and certainty—offer different discursive and artistic tactics. They construct a conversation between different improvisational attitudes in life and art, affording the opportunity for deeper scrutiny and creative exploration.

Taken together, the papers raise a common set of questions: how can a deeper understanding of the dynamic tension between doubt, certainty, and failure inform improvisation within artistic disciplines in a distinctive way? How might this different understanding feedback into life itself to inform research and practice in other fields beyond art, or in the arts' diverse relationships in the world? How might this diversity be increased in an informed, skilful way to enrich and energise social, cultural, and ecological systems? We invite our readers to entertain these questions and to raise new ones in the process of engaging with these texts.

\section{Acknowledgements}

The Special Issue Editors extend warm thanks to the CSI/ECI team: Editor Frederique Arroyas; Book Reviews Editor Rob Wallace; Managing Editor Michelle Peek; David Lee, Mark Kaethler, and Leslie Allin for their copyediting/proofreading expertise; and Wayne Johnston and his staff at the University of Guelph library for their invaluable support.

We are grateful to Gaelyn and Gustavo Aguilar for granting us permission to display their work on this issue's splash page. The photo was taken by Gaelyn Aguilar. The audio is Gustavo Aguilar's realization of Earle Brown's November 1952 open graphic score, performed here on Home Appliances, Children's Toy, and Harmonica. We would also like to acknowledge Tacita Dean/ Frith Street Gallery, London and Marian Goodman Gallery, New York/Paris for permission to use images of Dean's work in Andrew Sneddon's essay; and the Kolkata Sukriti Foundation for permission to show a clip within Basu's essay, taken from the film Metamorphosis directed by Abhijit Dasgupta. 
Critical Studies in Improvisation / Études critiques en improvisation, Vol 8, No 2 (2012)

\section{Notes}

${ }^{1}$ This Special Issue grew out of the panel The art of improvisation (P33) convened by its editors at the annual conference of the Association of Social Anthropologists of the UK and Commonwealth, held at Jawaharlal Nehru University, New Delhi, India, 3-6 April 2012, and entitled Art and Aesthetics in a Globalising World. 